\title{
Arterial stiffness in diabetes and the metabolic syndrome: a pathway to cardiovascular disease
}

\author{
C. D. A. Stehouwer • R. M. A. Henry • I. Ferreira
}

Received: 27 September 2007 / Accepted: 8 November 2007 /Published online: 1 February 2008

(C) Springer-Verlag 2008

\begin{abstract}
Increased arterial stiffness associated with diabetes and the metabolic syndrome may in part explain the increased cardiovascular disease risk observed in these conditions. Arterial stiffness can be estimated by quantifying pulse pressure but is better described by distensibility and compliance coefficients, pulse wave velocity and wave reflection. The most common non-invasive methodologies used to quantify these estimates of arterial stiffness (e.g. ultrasonography and applanation tonometry) are also described. We then review and summarise the current data on the associations between diabetes, the metabolic syndrome and insulin resistance on the one hand and greater arterial stiffness on the other, and identify and discuss some unresolved issues such as differential stiffening of central vs peripheral arterial segments, the impact of sex, and the pathobiology of increased arterial stiffness in diabetes and the metabolic syndrome. Finally, some considerations with regard to treatment options are presented.
\end{abstract}

This review is based in part on the Camillo Golgi Lecture given by C. D. A. Stehouwer at the 41 st annual meeting of the EASD in Athens, Greece, 2005.

Electronic supplementary material The online version of this article (doi:10.1007/s00125-007-0918-3) contains supplementary material, which is available to authorised users.

C. D. A. Stehouwer $(\bowtie) \cdot$ R. M. A. Henry $\cdot$ I. Ferreira Department of Internal Medicine, University Hospital Maastricht, P. Debyelaan 25, P.O. Box 5800, 6202 AZ Maastricht,

The Netherlands

e-mail: csteh@sint.azm.nl

\section{Ferreira}

Department of Clinical Epidemiology and Medical

Technology Assessment, University Hospital Maastricht,

Maastricht, The Netherlands
At present the most powerful therapy available for reducing arterial stiffness is to vigorously treat hypertension using pharmacological agents. New pharmacological strategies to reduce arterial stiffness are likely to be especially relevant to individuals with diabetes.

Keywords Arterial stiffness · Cardiovascular disease . Diabetes $\cdot$ Insulin resistance $\cdot$ Metabolic syndrome . Pathophysiology

\begin{abstract}
Abbreviation
AGEs advanced glycation end-products
\end{abstract}

\section{Introduction}

Cardiovascular disease is the main cause of death in both type 1 and type 2 diabetes mellitus [1]. The pathophysiological mechanisms underlying these associations are incompletely understood. Increased arterial stiffness may be one important pathway linking diabetes to the increased cardiovascular risk, as it commonly occurs in these conditions [2]. Indeed, increased arterial stiffness predicts the development of cardiovascular disease and mortality in the general population [3] and in type 2 diabetes [4].

To illustrate the problem of arterial stiffness in the context of clinical practice we introduce a clinical case (see text box: Arterial stiffness- the clinical problem). Mrs T's main problem was not obesity or poor glycaemic control, but, rather, severe systolic hypertension and relatively low diastolic blood pressure (i.e. elevated pulse pressure). We explain below that Mrs T's underlying cause of death may have been arterial stiffening. 


\section{Arterial stiffness-the clinical problem \\ Mrs T \\ At the age of 70 years: \\ - duration of diabetes 12 years \\ - BMl $28 \mathrm{~kg} / \mathrm{m}^{2}$ \\ - $\mathrm{HbA}_{1 \mathrm{c}} 7.1 \%$ \\ - blood pressure $186 / 68 \mathrm{mmHg}$ \\ - five antihypertensives}

At the age of 72: myocardial infarction and heart failure At the age of 74 : death from stroke

Arterial stiffness - why is it important?

Pulse pressure is now recognised as a strong predictor of cardiovascular disease, particularly in older people. This is illustrated by data from the Framingham Heart Study showing that the risk of coronary heart disease increased with increasing levels of systolic blood pressure, but, and at the same time, for each level of systolic blood pressure the risk was actually higher at the lowest levels of diastolic pressure (i.e. at the widest pulse pressure) [5] (Fig. 1). Pulse pressure depends on the stroke volume ejected by the left ventricle, the cushioning capacity of the arterial system (i.e. the ability of arteries, mainly the aorta, to smooth flow pulsations imposed by the intermittent contracting heart so that the blood is directed through the organs and tissues in an almost steady stream), and the amplitude and timing of arterial wave reflection $[6,7]$. Arterial stiffness (i.e. impairment of the cushioning capacity) leads to an increase in systolic blood pressure because hearts ejecting into a stiffer arterial bed must generate

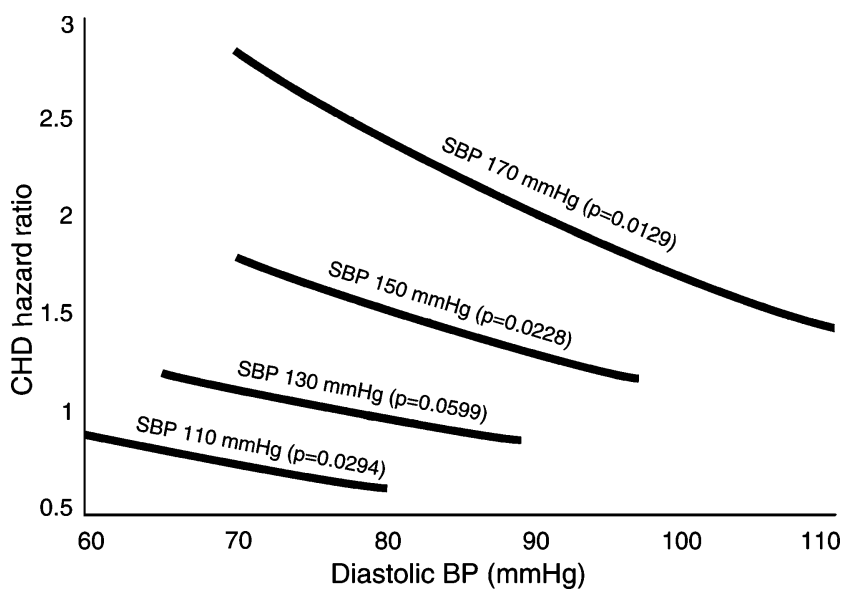

Fig. 1 Coronary heart disease (CHD) risk according to systolic, diastolic and pulse pressure in the Framingham Heart Study. The figure depicts that any increase in systolic blood pressure (SBP) is associated with an increase in CHD risk; however, and at the same time, for each SBP the highest CHD risk is actually observed at the lowest DBP level, i.e. at the highest pulse pressure (PP) level. Reproduced with permission from Lippincott Williams \& Wilkins [5] higher end-systolic pressures for the same net stroke volume. This leads to increased decay of arterial pressure and volume during systole, causing a reduced arterial volume at the onset of diastole, which in turn causes an enhanced fall in diastolic blood pressure [8]. Greater arterial stiffness also increases systolic and decreases diastolic pressure through increasing pulse wave velocity and through arterial wave reflection (see below). The direct clinical consequences of increased arterial stiffness are an increased risk of stroke as a result of increased systolic pressure; the development of left ventricular hypertrophy as a result of increased cardiac afterload; and a decrease in coronary perfusion and heart failure owing to the decrease in diastolic blood pressure.

Systolic blood pressure increases progressively with increasing age, whereas a decrease in diastolic blood pressure is observed particularly from the 5th decade onwards [9]. Because ventricular ejection decreases with age, arterial stiffness assumes a critical role in the explanation of the age-related

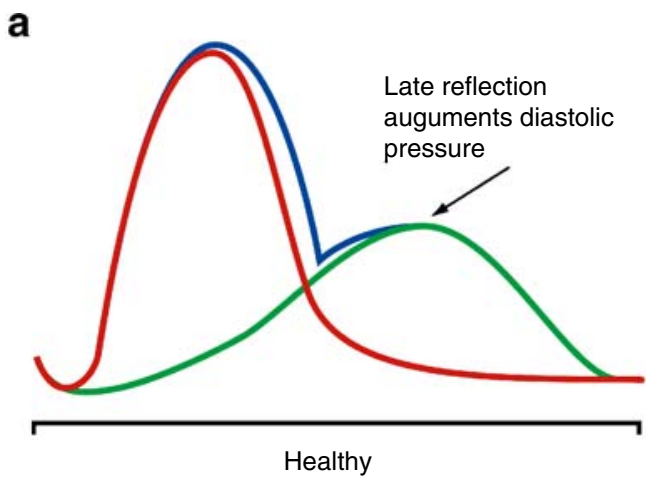

b

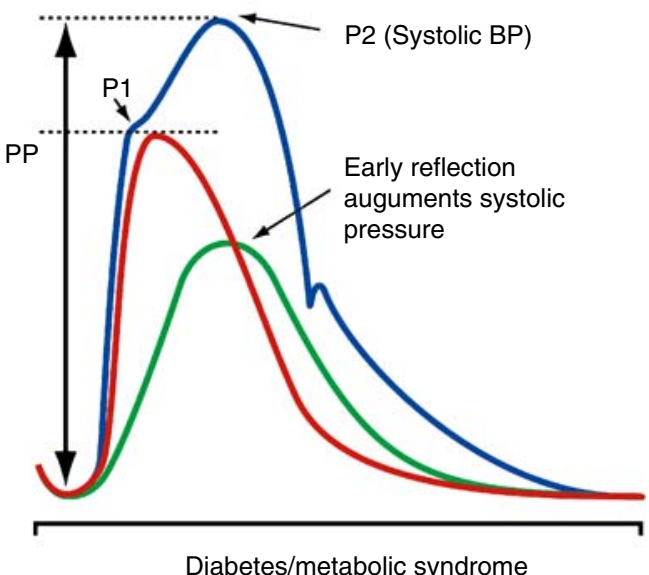

Fig. 2 Illustration of the combination of forward (red line) and the sum of many reflected waves (green line) and its impact on the measured pulse wave (blue line). In elastic vessels (e.g. healthy individuals) reflection occurs during diastole (a), whereas in stiff vessels (e.g. diabetes and the metabolic syndrome) wave reflection occurs during systole leading to an amplification of the systolic BP and pulse pressure (PP) (b). P1, systolic peak of the forward (first) wave; P2, systolic peak of the augmented (measured) wave. Adapted from [11] 
increases in systolic and pulse pressure and related mortality, and this therefore explains why brachial pulse pressure is commonly used as a marker of arterial stiffness [7].

Despite their utility in clinical practice, cuff sphygmomanometer measures of blood pressure are not sufficient to understand the underlying processes explaining the increase in pulse pressure for two main reasons: first, they do not depict the phenomenon of arterial wave reflection, and second, they are not appropriate for the detection of artery stiffening in early stages because of the phenomenon of pulse pressure amplification between central and peripheral arteries observed in young individuals [10]. As the pressure wave generated by cardiac ejection is transmitted forward from the central aorta to the periphery and is reflected back from any point of impedance discontinuity (e.g. arterial branching and arterialarteriolar junctions), the arterial pressure waveform recorded in any arterial site (e.g. the ascending aorta or brachial artery) is thus the result of the summation of the forward and backward pressure waves at that specific site. In elastic arteries, reflected waves arrive at the aorta during diastole, as usually observed in young and healthy subjects, whereas in stiff arteries the reflected pressure wave returns during early systole, adding to the forward wave and augmenting the systolic and pulse pressure, as usually observed in the elderly and in hypertensive individuals [11] (Fig. 2). In addition, elastic properties of large conduit arteries vary along the arterial tree, owing to cellular and histological differences in the structure of the arterial wall): proximal arteries (e.g. aorta) are more elastic and distal arteries (e.g. brachial or femoral) are stiffer. This heterogeneity is important because the pressure wave propagated along the arterial tree is progressively amplified from central to peripheral arteries as a result of wave reflections. In peripheral arteries, wave reflection can amplify pressure because the reflection sites are closer than in central arteries, which explains why, particularly in young individuals, brachial pulse pressure is higher than aortic pulse pressure. However, because ageing stiffens central arteries to a greater extent than peripheral arteries, the amplification between central and peripheral arteries is attenuated. Therefore, in the young, the use of brachial pulse pressure as a marker of arterial stiffness is not appropriate [7].

\section{Estimates of arterial stiffness}

An overview of methods and calculation details is shown in the text box 'Definitions of the most commonly used indices of arterial stiffness'. Arterial stiffness can either be estimated locally at specific arterial sites (e.g. carotid, radial, brachial

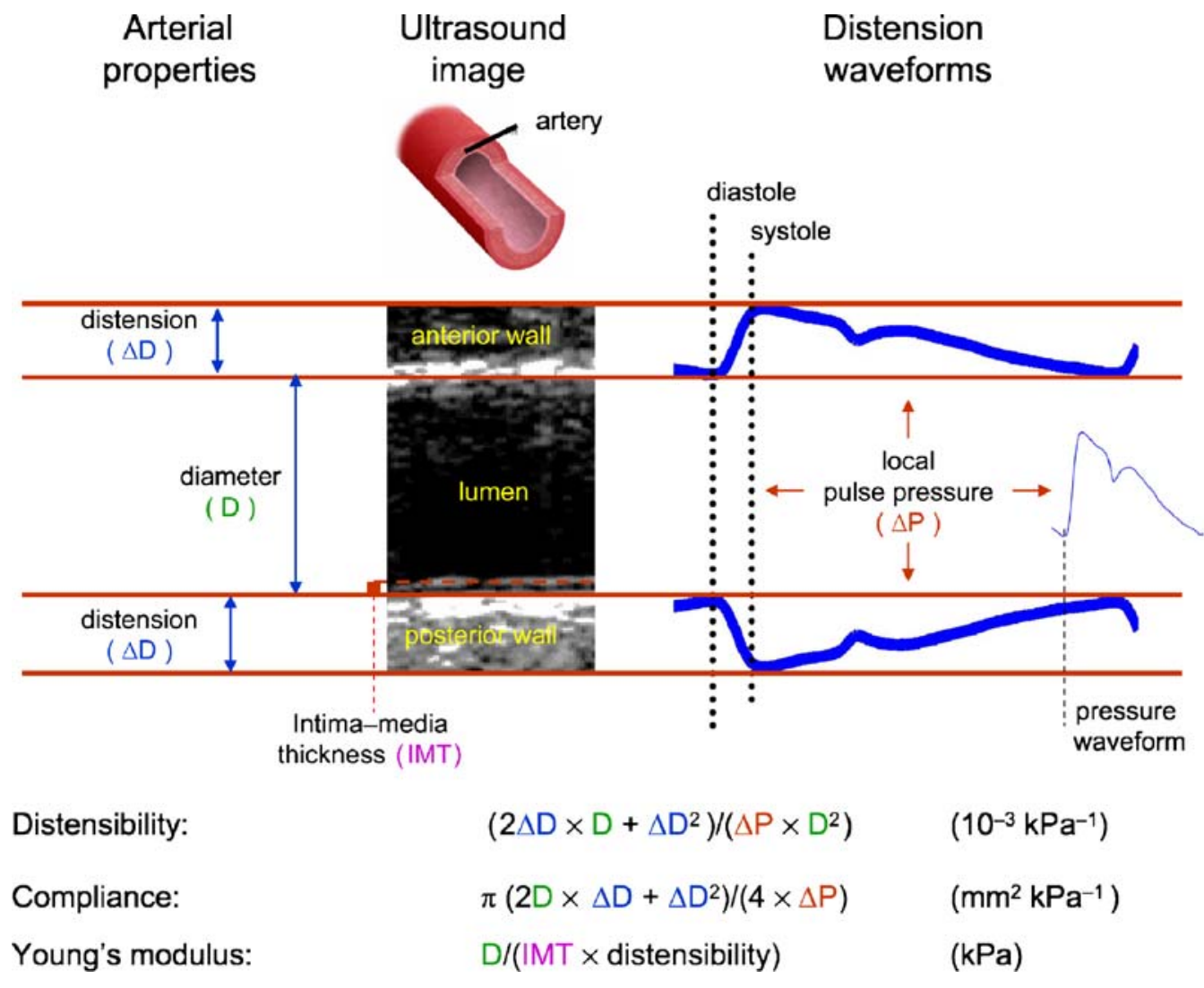

Fig. 3 Ultrasound-derived arterial properties to determine local arterial stiffness. The two thick blue lines represent the vessel wall movement during the cardiac cycle 
and femoral) or regionally over a given arterial segment length (e.g. the aorta or the upper or lower limb) [3]. Local estimates of arterial stiffness are most often described in terms of compliance and distensibility coefficients, and are usually obtained through measurement of arterial changes in diameter or area and local distending pressure by means of ultrasound imaging (Fig. 3). Regional estimates of arterial stiffness are obtained through measurement of the speed of pulse pressure wave propagation, i.e. pulse wave velocity along an arterial segment. Pressure sensors (i.e. mechanotransducers or applanation tonometers) are applied at two arterial sites to record pressure waveforms and the transit time that the pressure wave took to travel between the two arterial sites; pulse wave velocity is then calculated as the distance/travel time. Pulse wave velocity measured along the aorto-iliac pathway, i.e. carotid-femoral pulse wave velocity, is the most commonly used measure of arterial stiffness, given its proven value as a predictor of cardiovascular disease and mortality. The local and regional stiffness estimates described above are, however, closely related conceptually. This is illustrated by the fact that if arterial diameter falls while distending pressure is kept constant (i.e. an increase in stiffness), the speed with which the pressure wave travels increases [3]. In addition, analysis of the arterial pulse waveform using applanation tonometry is used to measure the augmentation in pulse pressure that is due to pulse wave reflection. Good quality registration of the arterial pressure waveform is obtained by applanating (flattening) a superficial artery (usually the radial) supported by bone using an external tonometer. This peripheral pressure waveform is then transformed, usually with the use of a transfer function, into a central arterial shape, i.e. that of the ascending aorta, which represents the true load imposed to the left ventricle. Analysis of this central waveform identifies the systolic peak of the forward wave and the systolic peak of the augmented wave; the difference between these two values expressed relative to pulse pressure represents the augmentation of the pulse pressure due to wave reflection [3] (Fig. 2).

The stiffness of an arterial site or segment is dependent on its background level of distending pressure, i.e. mean arterial pressure - a greater recruitment of relatively inelastic collagen fibres occurs with increasing distending pressures, enhancing stiffness. Therefore, to fully appreciate arterial stiffness estimates in clinical studies, adjustment for mean arterial pressure levels is imperative so that the distending pressure effects can be differentiated from true differences in viscoelastic properties of the arterial wall [12].

For an extensive theoretical review of the haemodynamic principles and models underlying the definitions and assessment methods of the arterial stiffness estimates described above, the reader is referred to the recent Expert Consensus document on arterial stiffness recently published by Laurent et al. [3], as this is beyond the scope of this review.
Arterial stiffness in diabetes and the metabolic syndrome: the evidence

As the literature up to 1999 has been extensively reviewed [13], we shall focus on recent developments. In addition, and in the context of type 2 diabetes, we also review the evidence with regard to the association between the metabolic syndrome and arterial stiffness, as clustering of cardiovascular risk factors precedes the development of diabetes $[14,15]$, and understanding their impact on arterial stiffness may be critical for the primary prevention of diabetes-related macrovascular disease. Finally, we discuss the evidence with regard to the role of insulin resistance.

Type 1 diabetes mellitus A large body of evidence supports the concept of increased arterial stiffness in type 1 diabetes [16-26] [Electronic supplementary material (ESM) Table 1]. This is an early phenomenon that occurs before the onset of clinically overt micro- or macrovascular disease $[17,18,22$, 24, 26-29], and arterial stiffness is further enhanced in the presence of microvascular complications (e.g. nephropathy, microalbuminuria or retinopathy) $[17,25,30]$. Similar findings have been reported with regard to pulse pressure: in individuals with type 1 diabetes an increase in pulse pressure can be detected as early as the third and fourth decade of life, i.e. there is accelerated arterial ageing, and the age-pulse pressure relationship is even steeper in the presence of microvascular complications [31, 32] (Fig. 4). It is, however, not clear whether increased arterial stiffness is a cause (because greater arterial stiffness is associated with greater pressures in small arteries and capillaries) or a consequence (because microvascular dropout will increase wave reflection and thus increase pulse pressure [33]) of microangiopathy, or alternatively, that both phenomena derive from a common antecedent (e.g. endothelial dysfunction or inflammation) [34, 35]. Importantly, greater pulse pressure in type 1 diabetic patients is associated with incident cardiovascular mortality [32]. Taken together, these data support the concept of accelerated arterial ageing in type 1 diabetes and may explain, at least in part, the increased cardiovascular risk in these patients.

Type 2 diabetes mellitus Similar to type 1 diabetes, a large body of evidence supports the concept of increased arterial stiffness in type 2 diabetes [36-53] (ESM Table 2). This again is an early phenomenon as much already occurs in the impaired glucose metabolism state (i.e. impaired fasting glucose and/or impaired glucose tolerance) $[42,44,48,53$, 54] (Fig. 5). These findings support the so-called 'common soil' or 'ticking clock' hypothesis, which suggests that macrovascular disease associated with type 2 diabetes begins in the pre-diabetic state $[15,55]$. In addition, the presence of micro- and macrovascular complications in type 2 diabetes is associated with a further increase in arterial stiffness [37, 41, 


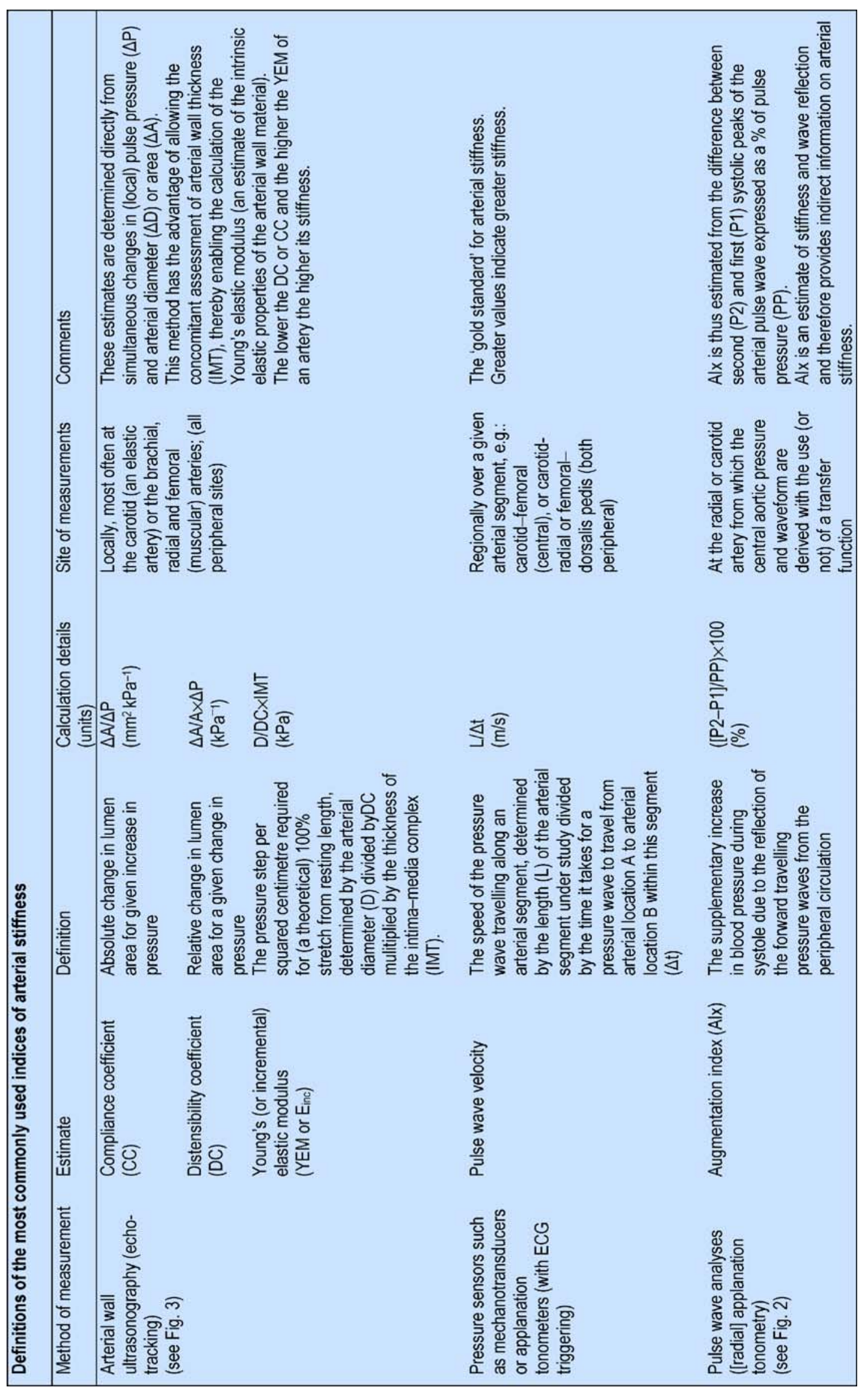




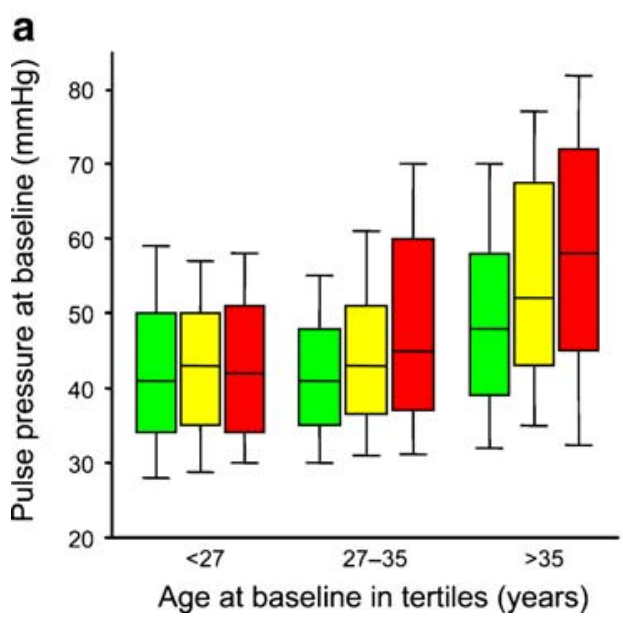

Fig. 4 The association of pulse pressure with age among type 1 patients is stronger in the presence of micro- or macroalbuminuria (a) or proliferative or proliferative retinopathy (b) than in their absence (The EURODIAB Study). Green boxes, normoalbuminuria; yellow boxes, microalbuminuria; red boxes, macroalbuminuria; hatched green

50, 56-59]. Furthermore, as in type 1 diabetes, the agerelated increase in arterial stiffness is steeper in individuals with type 2 diabetes than in their non-diabetic counterparts $[36,40,43,46]$. This is consistent with observations of steeper increases in pulse pressure with ageing in these patients [60] (Fig. 6): these increases are further amplified in the presence of micro- and macrovascular complications [61-63]. Importantly, the increased pulse pressure observed in type 2 diabetic patients has been found to be predictive of future cardiovascular mortality $[60,64]$.

Metabolic syndrome Studies investigating the association between the metabolic syndrome and arterial stiffness have

a

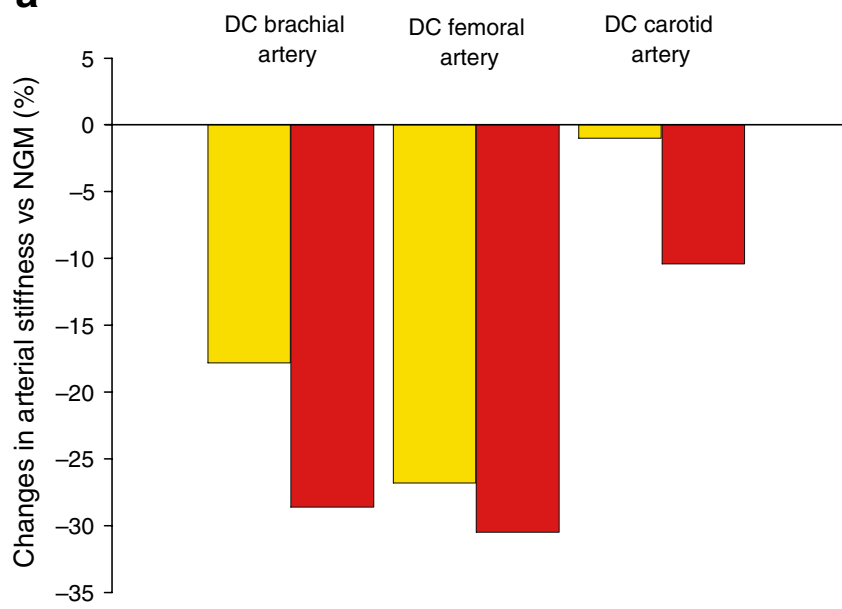

Fig. 5 Relative changes in peripheral arterial stiffness (local arterial distensibility coefficients [DC] of the brachial, femoral and carotid arteries) (a), and central arterial stiffness (systemic compliance, carotid-femoral transit time and aortic augmentation index) (b) in individuals with type 2 diabetes and impaired glucose metabolism

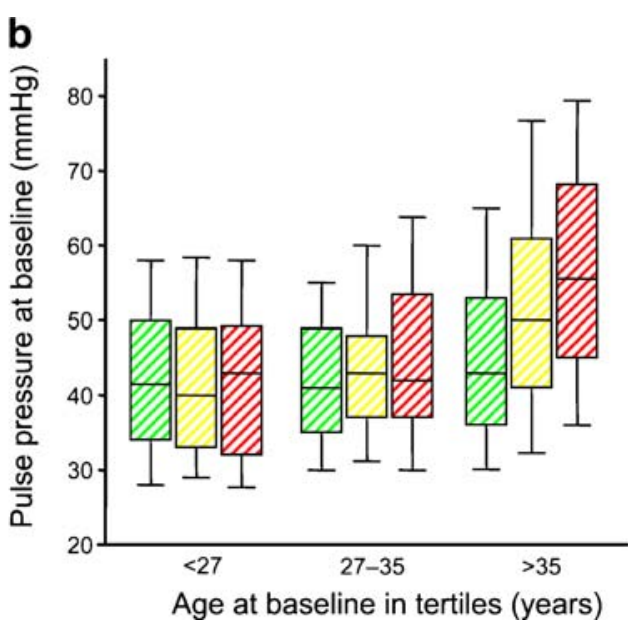

boxes, no retinopathy; hatched yellow boxes, non-proliferative retinopathy; hatched red boxes, proliferative retinopathy. The box plots show the median, interquartile range and standard error. Reproduced from [32] with the permission of Lippincott Williams \& Wilkins

consistently shown increased arterial stiffness in individuals with the metabolic syndrome or with increasing number of traits of the metabolic syndrome [45, 65-87] (ESM Table 3). Importantly, such deleterious arterial changes have been shown at a very young age (e.g. in obese [78] and apparently healthy adolescents [76] and young adults [70, 71, 84]) (Fig. 7). The increased stiffness in the metabolic syndrome thus appears to be caused by subtle metabolic abnormalities (and not by fully developed diabetes), which supports the ticking clock hypothesis mentioned above. In addition, prospective studies have shown that the increase in arterial stiffness with age is greater in individuals with the metabolic syndrome as compared with those without [66, 81]. Impor-

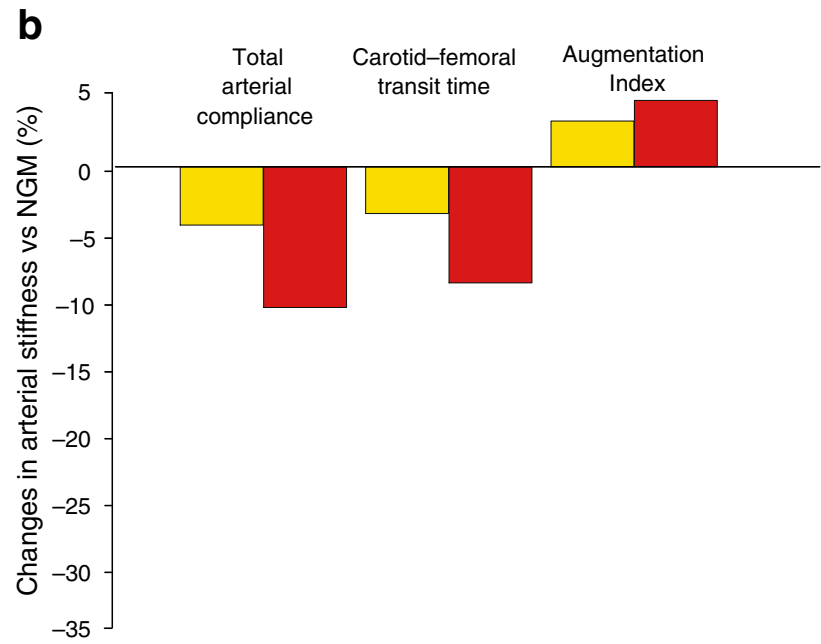

compared with those with normal glucose metabolism (the Hoorn Study). Yellow bars, impaired glucose metabolism, red bars, type 2 diabetes. NGM, normal glucose metabolism. Reproduced with permission from Lippincott Williams \& Wilkins [48] 


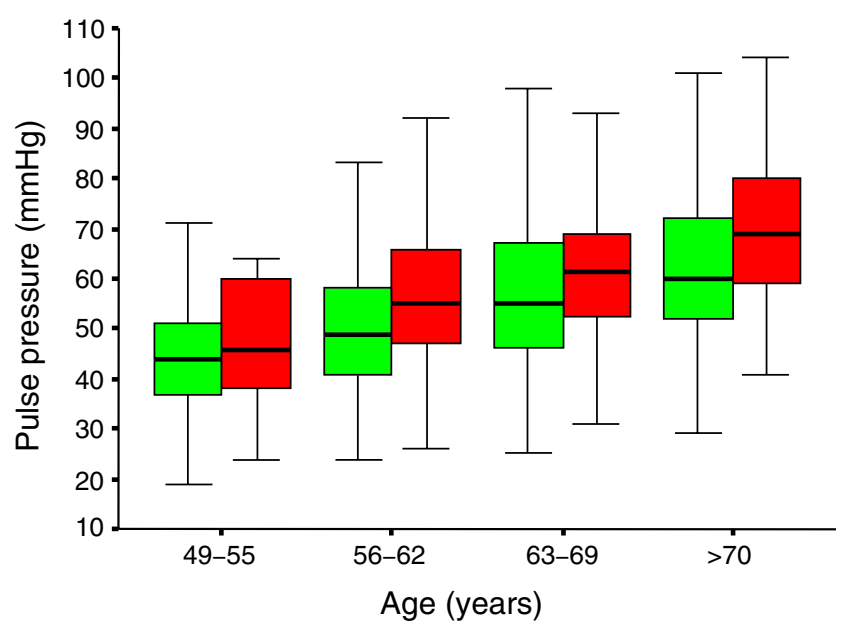

Fig. 6 Arterial ageing in type 2 diabetes. There is a steeper increase in pulse pressure with age in type 2 diabetic (red boxes) than in nondiabetic individuals (green boxes). The box plots show the median, interquartile range and standard error. Reproduced with permission from Lippincott Williams \& Wilkins [60]

tantly, individuals whose metabolic syndrome status has regressed or remained negative over time show lower rates of increase in arterial stiffness [82].

Taken together, these data support the concept of increased arterial stiffness in the metabolic syndrome, which may explain, at least in part, the increased cardiovascular risk in these individuals, and emphasise the importance of primary prevention. It is important to stress that the association between (traits of) the metabolic syndrome and arterial stiffness is not only related to higher blood pressure; in addition to (and independently of) blood pressure, (central) obesity and increased fasting glucose levels were the traits consistently associated with arterial stiffness, whereas dyslipidaemia was less so. These are the three traits that are most often observed in combination, and this clustering is associated with the greatest mortality risk [88]. Analyses of the metabolic syndrome traits and their clustering expressed as a continuous score and the close examination of each trait (and/or combination of traits) in relation to increased arterial stiffness may therefore be a more appropriate approach in aetiological studies (for an example, see [84]).

The role of insulin resistance Insulin resistance usually precedes the development of type 2 diabetes and is often accompanied by a clustering of the risk factors characteristic of the metabolic syndrome. Recent mechanistic studies performed in humans have suggested that increased stiffness could be yet another feature of insulin resistance [89]. Insulin, at physiological concentrations, has acute vasodilatory effects that lead to increased arterial distensibility; however, these beneficial effects are blunted in insulin-resistant states such as obesity/ the metabolic syndrome and type 1 diabetes and type 2 diabetes, and are closely related to whole-body glucose uptake
[89]. The chronic effects of insulin resistance on arterial stiffness have also been examined. In healthy individuals, a positive association between insulin-mediated glucose uptake and arterial distensibility was observed, although this effect was confined to the femoral artery and was more pronounced in women [90]. In a large population-based study, insulin concentrations (a more indirect measure of insulin sensitivity) were associated with carotid artery stiffness, and this association was also stronger in women than in men [91]. Also in diabetic patients, inverse associations were observed between clamp-measured insulin sensitivity and arterial stiffness in the carotid [92, 93] and femoral [93] arteries. Importantly, because arterial stiffness is highly dependent on blood pressure and hypertension itself affects the stimulation

a

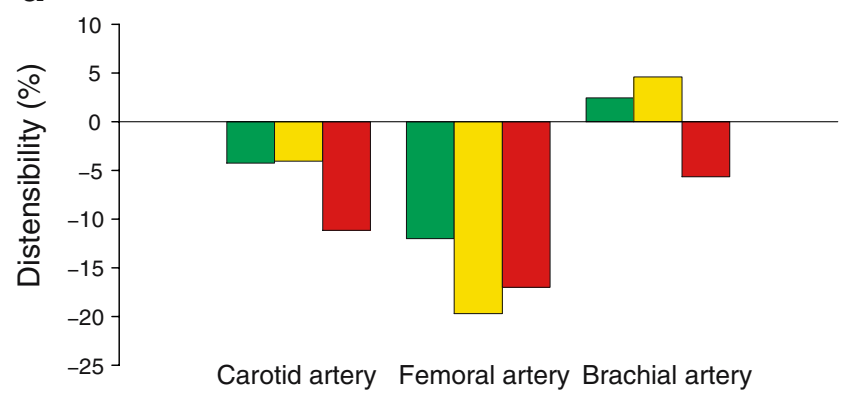

b

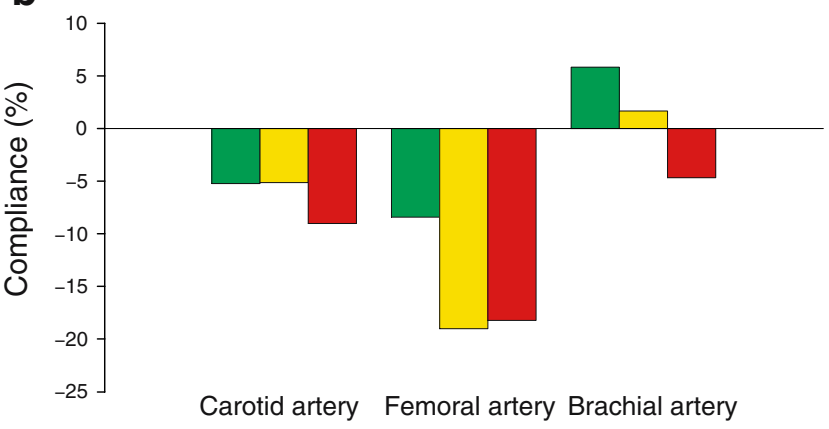

C

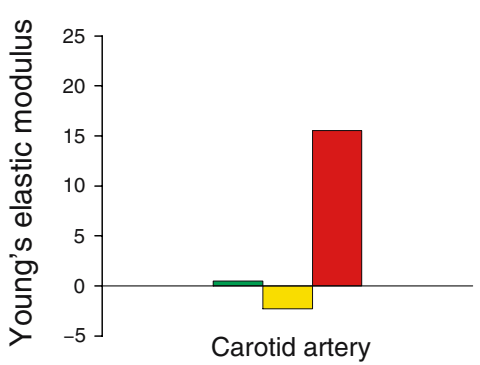

Fig. 7 Relative change in arterial stiffness estimates according to number of risk factors (RFs) of the metabolic syndrome (MetS) as compared with no risk factors; distensibility (a) and compliance (b) of the carotid, femoral and brachial arteries, and (c) Young's elastic modulus of the carotid artery (The Amsterdam Growth and Health Longitudinal Study). Green bars, 1 RF; yellow bars; 2 RFs; red bars, $\geq 3$ RFs (MetS). Reproduced from [70] with permission from the American Medical Association 


\section{Arterial stiffness in diabetes and the metabolic syndrome-review of the evidence}

- Arterial stiffness is increased in type 1 diabetes

—this is an early phenomenon that occurs before the onset of clinically overt micro- or macrovascular complications

- Arterial stiffness is increased in type 2 diabetes

-this is an early phenomenon, as much occurs in the impaired glucose metabolism state

-the presence of micro- and macrovascular complications is associated with a further increase in arterial stiffness

- Arterial stiffness is also increased in the metabolic syndrome and in insulin-resistant states — subtle changes in metabolic variables (not fully developed diabetes) affect arterial stiffness from an early age

Diabetes is a disease of accelerated arterial ageing, as shown by stiffer arteries and consequent steeper increases in pulse pressure with age in these subjects

of glucose uptake by insulin, it is noteworthy that the studies mentioned above have shown insulin resistance to be associated with estimates of arterial stiffness even after adjustments for mean arterial pressure levels. In this respect, recent studies have shown additive adverse effects of insulin resistance on arterial stiffness in the context of hypertension [94, 95]. Notably, in the only longitudinal study that has addressed the individual and combined effects of raised blood pressure and raised glucose levels on the progression of arterial stiffness, the estimated rate of increase in arterial stiffness was higher in individuals with both abnormalities than in those with either abnormality alone [96]. Most importantly, persistence of both abnormalities synergistically accelerated the rate of increase in arterial stiffness such that it was three times higher than in those who persisted with elevated levels of blood pressure or glucose alone. In conclusion, insulin resistance contributes to increased arterial stiffness independently of blood pressure in type 2 diabetic patients but also in apparently healthy individuals.

Unresolved issues in diabetes- and metabolic syndrome-related arterial stiffening

\section{Preferential stiffening of peripheral over central arteries?}

One important issue is whether the association between diabetes (or the metabolic syndrome) and arterial stiffening differs between central and peripheral arteries. This question has been raised by the conflicting results published by the relatively few studies examining arterial stiffness in several arterial territories within the same individual. Discrepancies detected may be due to the use of different methods (i.e. regionally or locally) in the assessment of estimates of arterial stiffness and/or the different histological features (i.e. the elastin to collagen ratio that decreases from proximal to distal sites) of the arterial tree, which may have different susceptibilities to risk factors.

Studies in which regional stiffness estimates have been compared in different arterial segments have shown diabetes or the metabolic syndrome to preferentially affect the central rather than the peripheral part of the arterial tree $[43,50,73]$ or to have a similar impact on the stiffness of central and peripheral segments $[47,51,84]$. In contrast, in studies where stiffness estimates have been assessed locally at different (mainly peripheral) arterial sites, the deleterious effects of diabetes or the metabolic syndrome were stronger at the more muscular (i.e. radial, brachial and femoral) rather than the more elastic (i.e. the carotid) arteries [17, 42, 48, 70, 90]. However, preferential stiffness of elastic over muscular arteries has also been shown [21, 97]. Because most of the studies reviewed herein have investigated one particular vascular territory only (see ESM Tables 1, 2, 3), no consistent picture has as yet emerged with regard to preferential central or peripheral stiffening in either diabetes or the metabolic syndrome, which hampers pathophysiological interpretation of these data. Preferential stiffness of peripheral arterial segments or sites would suggest that the cushioning function of the central circulatory system would be relatively preserved over the peripheral conduit function, which would facilitate cardiac stroke volume expulsion into a circulatory system that increasingly stiffens with age. 
Central vs peripheral stiffness as cardiovascular risk factor Studies demonstrating the prognostic value of arterial stiffness in the prediction of cardiovascular events have been almost all confined to estimates of stiffness of elastic arterial segments or sites (i.e. aortic pulse wave velocity and carotid distensibility) [3]. Whether stiffness of muscular segments or sites has the same predictive value is largely unknown. So far, this has been investigated in one study only, where central but not peripheral arterial stiffness was an independent predictor of death in a cohort of haemodialysis patients [98]. Similarly, a recent study showed that central rather than peripheral arterial stiffness was elevated in type 2 diabetes patients with ischaemic heart disease [99]; however, its cross-sectional design does not allow the conclusion of a greater prognostic value of central over peripheral stiffness in the diabetic population. Nevertheless, peripheral arterial stiffness may be clinically relevant as it has been shown to be closely associated with prevalent peripheral vascular disease $[100,101]$, which is a clinically important outcome in the (pre-)diabetic population. Additional studies to clarify these issues are needed.

The impact of sex Several studies suggest that the cardiovascular morbidity associated with diabetes [102, 103], like that associated with the metabolic syndrome [104, 105], is greater in women than in men. Moreover, unlike men with diabetes, it seems that women with this disease have not experienced a decline in coronary heart disease mortality [106]. Potentially, this discrepancy could be explained by greater arterial stiffness in women with diabetes or the metabolic syndrome, although this is not clear from the current literature. The majority of previous studies have either undertaken sexadjusted analyses or have been performed in single-sex cohorts (ESM Tables 1, 2, 3). Studies that have examined the strength of the associations between diabetes or the metabolic syndrome and arterial stiffness in men and women separately have disclosed no sex differences $[21,72,83]$ or have shown these associations to be somewhat stronger in women than in men [23, 46, 67, 71, 80, 84, 85, 97]. Overall, these findings suggest that analyses of data in men and women separately may be more appropriate.
The pathobiology of increased arterial stiffness in diabetes and the metabolic syndrome

Increased arterial stiffness is primarily determined by the properties of the extracellular matrix (elastin, collagen) and vascular smooth muscular cell function [107, 108]. These variables are strongly affected by aging and blood pressure, which cause repetitive pulsatile stress upon the arterial wall, leading to both structural and functional disruption of the arterial pressure load-bearing elastin-collagen network within the media (e.g. fracturing of elastin fibres resulting from mechanical fatigue and altered pressure-dependent recruitment of [excessive] collagen fibres) [11]. How arterial stiffness is increased in diabetes and the metabolic syndrome is largely unknown [11, 34, 108, 109]. One of the main mechanisms thought to be involved, particularly in diabetic individuals, is the formation of advanced glycation endproducts (AGEs) on the arterial wall, causing cross-linking of collagen molecules, which may lead to loss of collagen elasticity and a subsequent increase in arterial stiffness [110]. Indeed, AGEs have been associated with greater stiffness in diabetic patients [111, 112], and cross-link breakers have been demonstrated to decrease arterial stiffness in humans [113]. Chronic hyperglycaemia and hyperinsulinaemia also increase the local activity of the renin-angiotensinaldosterone system and expression of angiotensin type I receptor in vascular tissue, promoting development of wall hypertrophy and fibrosis [109]. In addition, low-grade inflammation and endothelial dysfunction, which are interrelated, may also explain, at least in part, the increases in arterial stiffness related to diabetes and the metabolic syndrome [75, 84, 114]. Indeed, low-grade inflammation and endothelial dysfunction are common in diabetes and the metabolic syndrome $[34,35,109]$ and partially explain the increased cardiovascular risk in these conditions $[115,116]$. Endothelial dysfunction may lead to functional stiffening of large arteries as the reduced availability of nitric oxide and increased activity of vasoconstrictors such as endothelin-1 affect vascular smooth muscle cell tone [117-119]. In addition, endothelial dysfunction may lead to smooth muscle cell proliferation and increased synthesis of structural

\section{Arterial stiffness-unsolved issues and questions for the future \\ - Does diabetes preferentially affect the stiffness of peripheral over central arteries (or vice versa)? \\ -What is the prognostic value of an increased peripheral arterial stiffness observed in diabetes? \\ - Is the diabetes-related increase in arterial stiffness more pronounced in women? \\ -What are the pathophysiological mechanisms that underlie the associations between diabetes and metabolic syndrome and arterial stiffness?}


proteins such as collagen. Low-grade inflammation impairs endothelial function, which may therefore result in increased arterial stiffness [120]. However, prospective data to test the mediating role of endothelial dysfunction and/or inflammation on the metabolic syndrome and diabetes-related arterial stiffening are still lacking.

\section{Treatment}

At present the most powerful therapy to reduce arterial stiffness is vigorous treatment of hypertension with pharmacological agents. Indeed, many, but not all, of the current pharmacological strategies reduce arterial stiffness, but this is an indirect effect resulting from lowering of mean arterial pressure (for review see [121]). In fact, because antihypertensive drugs were primarily designed to reduce peripheral resistance, they may not alter the pathological process of arterial stiffening itself or electively reduce systolic blood pressure. This may explain why isolated systolic hypertension is so often resistant to pharmacological intervention. Whether some anti-hypertensives are more effective than others in this respect constitutes a current important area of investigation (cf. the Conduit Artery Function Evaluation [CAFÉ] study [122] and Regression of Arterial Stiffness in a Controlled Double-Blind Study [REASON] [123]). In addition, new strategies to reduce arterial stiffness [e.g. so-called AGE breakers such as Alagebrium (ALT 711)] are in development and are likely to be especially relevant to individuals with diabetes [124]. These pharmacological agents break down established AGE cross-links between proteins within the arterial wall, thereby reducing arterial stiffness [113], but more evidence is necessary to establish the clinical relevance of such drugs. Alternative strategies to reduce arterial stiffness may involve enhancing $\mathrm{NO}$ release from endothelial cells (e.g. by the use of 3-hydroxy-3-methyl-glutaryl-CoA reductase inhibitors), and/or changes in lifestyle patterns with the aim of increasing dietary intake of n-3 fatty acids and decreasing salt intake, increasing aerobic physical activity levels, and reducing body fatness $[108,125]$. None of these strategies, however, has unequivocally been shown to reduce arterial stiffness in diabetes or the metabolic syndrome, and more study of these issues is needed.

\section{Conclusion}

There is convincing evidence that diabetes and the metabolic syndrome are associated with greater arterial stiffness. The underlying pathobiology is complex and remains to be fully elucidated. However, greater arterial stiffness may, at least in part, explain the increased cardiovascular risk in individuals with diabetes and the metabolic syndrome. For the clinician, it is important to realise that greater brachial pulse pressure, particularly in middle-aged and older individuals but even in relatively young type 1 diabetic individuals, is a marker of greater arterial stiffening and thus a marker of greater cardiovascular risk. However, whether other estimates of arterial stiffness (e.g. aortic pulse wave velocity) can improve risk stratification in diabetes or the metabolic syndrome remains to be shown.

Duality of interest The authors declare that there is no duality of interest associated with this manuscript.

\section{References}

1. Ryden L, Standl E, Bartnik M et al (2007) Guidelines on diabetes, pre-diabetes, and cardiovascular diseases: executive summary. The Task Force on Diabetes and Cardiovascular Diseases of the European Society of Cardiology (ESC) and of the European Association for the Study of Diabetes (EASD). Eur Heart J 28:88-136

2. Stehouwer CD, Ferreira I (2006) Diabetes, lipids and other risk factors. In: Safar ME, O'Rourke MF (eds) Arterial stiffness in hypertension. Elsevier, London, pp 427-456

3. Laurent S, Cockcroft J, Van Bortel L et al (2006) Expert consensus document on arterial stiffness: methodological issues and clinical applications. Eur Heart J 27:2588-2605

4. Cruickshank K, Riste L, Anderson SG, Wright JS, Dunn G, Gosling RG (2002) Aortic pulse-wave velocity and its relationship to mortality in diabetes and glucose intolerance: an integrated index of vascular function. Circulation 106:2085-2090

5. Franklin SS, Khan SA, Wong ND, Larson MG, Levy D (1999) Is pulse pressure useful in predicting risk for coronary heart disease? The Framingham Heart Study. Circulation 100:354-360

6. O'Rourke M (1995) Mechanical principles in arterial disease. Hypertension 26:2-9

7. Safar ME, Levy BI, Struijker-Boudier H (2003) Current perspectives on arterial stiffness and pulse pressure in hypertension and cardiovascular diseases. Circulation 107:2864-2869

8. Nichols WW, O'Rourke MF (2005) McDonald's blood flow in arteries: theoretical, experimental and clinical principles. Hodder Arnold, London

9. Franklin SS (1999) Ageing and hypertension: the assessment of blood pressure indices in predicting coronary heart disease. J Hypertens Suppl 17:S29-S36

10. K, Kawakami M, O'Rourke MF (2006) Pulse wave analysis and pulse wave velocity: a review of blood pressure interpretation 100 years after Korotkov. Circ J 70:1231-1239

11. Greenwald SE (2007) Ageing of the conduit arteries. J Pathol 211:157-172

12. Van Bortel LM, Duprez D, Starmans-Kool MJ et al (2002) Clinical applications of arterial stiffness, Task Force III: recommendations for user procedures. Am J Hypertens 15:445-452

13. Asmar R (1999) Arterial stiffness and pulse wave velocity. Clinical applications. Elsevier, Amsterdam

14. Grundy SM (2006) Metabolic syndrome: connecting and reconciling cardiovascular and diabetes worlds. J Am Coll Cardiol 47:1093-1100

15. Haffner SM, Stern MP, Hazuda HP, Mitchell BD, Patterson JK (1990) Cardiovascular risk factors in confirmed prediabetic individuals. Does the clock for coronary heart disease start ticking before the onset of clinical diabetes. JAMA 263:2893-2898 
16. Brooks B, Molyneaux L, Yue DK (1999) Augmentation of central arterial pressure in type 1 diabetes. Diabetes Care 22:1722-1727

17. Giannattasio C, Failla M, Piperno A et al (1999) Early impairment of large artery structure and function in type I diabetes mellitus. Diabetologia 42:987-994

18. Parikh A, Sochett EB, McCrindle BW, Dipchand A, Daneman A, Daneman D (2000) Carotid artery distensibility and cardiac function in adolescents with type 1 diabetes. J Pediatr 137:465-469

19. Wilkinson IB, MacCallum H, Rooijmans DF et al (2000) Increased augmentation index and systolic stress in type 1 diabetes mellitus. QJM 93:441-448

20. Giannattasio C, Failla M, Grappiolo A, Gamba PL, Paleari F, Mancia G (2001) Progression of large artery structural and functional alterations in type I diabetes. Diabetologia 44:203-208

21. Ahlgren AR, Sundkvist G, Sandgren T, Lanne T (2002) Female gender increases stiffness of elastic but not of muscular arteries in type I diabetic patients. Clin Physiol Funct Imaging 22:409-415

22. Haller MJ, Samyn M, Nichols WW et al (2004) Radial artery tonometry demonstrates arterial stiffness in children with type 1 diabetes. Diabetes Care 27:2911-2917

23. Ahlgren AR, Astrand H, Sundkvist G, Lanne T (2005) Increased aortic stiffness is persistent in type 1 diabetic women: a followup study. Diabetologia 48:780-783

24. Stakos DA, Schuster DP, Sparks EA, Wooley CF, Osei K, Boudoulas H (2005) Cardiovascular effects of type 1 diabetes mellitus in children. Angiology 56:311-317

25. Tryfonopoulos D, Anastasiou E, Protogerou A et al (2005) Arterial stiffness in type 1 diabetes mellitus is aggravated by autoimmune thyroid disease. J Endocrinol Invest 28:616-622

26. Atabek ME, Kurtoglu S, Pirgon O, Baykara M (2006) Arterial wall thickening and stiffening in children and adolescents with type 1 diabetes. Diabetes Res Clin Pract 74:33-40

27. Berry KL, Skyrme-Jones RA, Cameron JD, O'Brien RC, Meredith IT (1999) Systemic arterial compliance is reduced in young patients with IDDM. Am J Physiol 276:H1839-1845

28. Kool MJ, Lambert J, Stehouwer CD, Hoeks AP, Struijker Boudier HA, Van Bortel LM (1995) Vessel wall properties of large arteries in uncomplicated IDDM. Diabetes Care 18:618-624

29. Lambert J, Pijpers R, van Ittersum FJ et al (1997) Sodium, blood pressure, and arterial distensibility in insulin-dependent diabetes mellitus. Hypertension 30:1162-1168

30. Lambert J, Smulders RA, Aarsen M, Donker AJ, Stehouwer CD (1998) Carotid artery stiffness is increased in microalbuminuric IDDM patients. Diabetes Care 21:99-103

31. Ronnback M, Fagerudd J, Forsblom C, Pettersson-Fernholm K, Reunanen A, Groop PH (2004) Altered age-related blood pressure pattern in type 1 diabetes. Circulation 110:1076-1082

32. Schram MT, Chaturvedi N, Fuller JH, Stehouwer CD (2003) Pulse pressure is associated with age and cardiovascular disease in type 1 diabetes: the Eurodiab Prospective Complications Study. J Hypertens 21:2035-2044

33. Struijker Boudier HA, Baumann M, Cohuet G, Safar ME (2006) Large arteries, microcirculation and the mechanism of hypertension. In: Safar ME, O'Rourke MF (eds) Arterial stiffness in hypertension. Elsevier, London, pp 21-33

34. Schalkwijk CG, Stehouwer CD (2005) Vascular complications in diabetes mellitus: the role of endothelial dysfunction. Clin Sci (Lond) 109:143-159

35. Schram MT, Chaturvedi N, Schalkwijk CG, Fuller JH, Stehouwer CD (2005) Markers of inflammation are cross-sectionally associated with microvascular complications and cardiovascular disease in type 1 diabetes - the EURODIAB Prospective Complications Study. Diabetologia 48:370-378

36. Taniwaki H, Kawagishi T, Emoto M et al (1999) Correlation between the intima-media thickness of the carotid artery and aortic pulse-wave velocity in patients with type 2 diabetes. Vessel wall properties in type 2 diabetes. Diabetes Care 22:1851-1857

37. Aoun S, Blacher J, Safar ME, Mourad JJ (2001) Diabetes mellitus and renal failure: effects on large artery stiffness. J Hum Hypertens 15:693-700

38. Brooks BA, Molyneaux LM, Yue DK (2001) Augmentation of central arterial pressure in type 2 diabetes. Diabet Med 18:374-380

39. Ravikumar R, Deepa R, Shanthirani C, Mohan V (2002) Comparison of carotid intima-media thickness, arterial stiffness, and brachial artery flow mediated dilatation in diabetic and nondiabetic subjects (The Chennai Urban Population Study [CUPS-9]). Am J Cardiol 90:702-707

40. Cameron JD, Bulpitt CJ, Pinto ES, Rajkumar C (2003) The aging of elastic and muscular arteries: a comparison of diabetic and nondiabetic subjects. Diabetes Care 26:2133-2138

41. Fukui M, Kitagawa Y, Nakamura N et al (2003) Augmentation of central arterial pressure as a marker of atherosclerosis in patients with type 2 diabetes. Diabetes Res Clin Pract 59:153-161

42. Henry RM, Kostense PJ, Spijkerman AM et al (2003) Arterial stiffness increases with deteriorating glucose tolerance status: the Hoorn Study. Circulation 107:2089-2095

43. Kimoto E, Shoji T, Shinohara K et al (2003) Preferential stiffening of central over peripheral arteries in type 2 diabetes. Diabetes 52:448-452

44. Ohnishi H, Saitoh S, Takagi S et al (2003) Pulse wave velocity as an indicator of atherosclerosis in impaired fasting glucose: the Tanno and Sobetsu Study. Diabetes Care 26:437-440

45. O’Neal DN, Dragicevic G, Rowley KG et al (2003) A crosssectional study of the effects of type 2 diabetes and other cardiovascular risk factors on structure and function of nonstenotic arteries of the lower limb. Diabetes Care 26:199-205

46. De Angelis L, Millasseau SC, Smith A et al (2004) Sex differences in age-related stiffening of the aorta in subjects with type 2 diabetes. Hypertension 44:67-71

47. Meyer C, Milat F, McGrath BP, Cameron J, Kotsopoulos D, Teede HJ (2004) Vascular dysfunction and autonomic neuropathy in type 2 diabetes. Diabet Med 21:746-751

48. Schram MT, Henry RM, van Dijk RA et al (2004) Increased central artery stiffness in impaired glucose metabolism and type 2 diabetes: the Hoorn Study. Hypertension 43:176-181

49. Tedesco MA, Natale F, Di Salvo G, Caputo S, Capasso M, Calabro R (2004) Effects of coexisting hypertension and type II diabetes mellitus on arterial stiffness. J Hum Hypertens 18:469473

50. Kimoto E, Shoji T, Shinohara K et al (2006) Regional arterial stiffness in patients with type 2 diabetes and chronic kidney disease. J Am Soc Nephrol 17:2245-2252

51. Strain WD, Chaturvedi N, Dockery F et al (2006) Increased arterial stiffness in Europeans and African Caribbeans with type 2 diabetes cannot be accounted for by conventional cardiovascular risk factors. Am J Hypertens 19:889-896

52. Tsuchiya M, Suzuki E, Egawa K et al (2005) Abnormal peripheral circulation in type 2 diabetic patients with normal ankle-brachial index associates with coronary atherosclerosis, large artery stiffness, and peripheral vascular resistance. Diabetes Res Clin Pract 70:253-262

53. van Popele NM, Elizabeth Hak A, Mattace-Raso FU et al (2006) Impaired fasting glucose is associated with increased arterial stiffness in elderly people without diabetes mellitus: the Rotterdam Study. J Am Geriatr Soc 54:397-404

54. van Dijk RA, Nijpels G, Twisk JW et al (2000) Change in common carotid artery diameter, distensibility and compliance in subjects with a recent history of impaired glucose tolerance: a 3year follow-up study. J Hypertens 18:293-300

55. Haffner SM, Mykkanen L, Festa A, Burke JP, Stern MP (2000) Insulin-resistant prediabetic subjects have more atherogenic risk 
factors than insulin-sensitive prediabetic subjects: implications for preventing coronary heart disease during the prediabetic state. Circulation 101:975-980

56. Hermans MM, Henry R, Dekker JM et al (2007) Estimated glomerular filtration rate and urinary albumin excretion are independently associated with greater arterial stiffness: the Hoorn Study. J Am Soc Nephrol 18:1942-1952

57. Rema M, Mohan V, Deepa R, Ravikumar R (2004) Association of carotid intima-media thickness and arterial stiffness with diabetic retinopathy: the Chennai Urban Rural Epidemiology Study (CURES-2). Diabetes Care 27:1962-1967

58. Yokoyama H, Aoki T, Imahori M, Kuramitsu M (2004) Subclinical atherosclerosis is increased in type 2 diabetic patients with microalbuminuria evaluated by intima-media thickness and pulse wave velocity. Kidney Int 66:448-454

59. Yokoyama H, Hirasawa K, Aoki T, Ishiyama M, Koyama K (2003) Brachial-ankle pulse wave velocity measured automatically by oscillometric method is elevated in diabetic patients with incipient nephropathy. Diabet Med 20:942-945

60. Schram MT, Kostense PJ, Van Dijk RA et al (2002) Diabetes, pulse pressure and cardiovascular mortality: the Hoorn Study. J Hypertens 20:1743-1751

61. Knudsen ST, Poulsen PL, Hansen KW, Ebbehoj E, Bek T, Mogensen CE (2002) Pulse pressure and diurnal blood pressure variation: association with micro- and macrovascular complications in type 2 diabetes. Am J Hypertens 15:244-250

62. Smith A, Karalliedde J, De Angelis L, Goldsmith D, Viberti G (2005) Aortic pulse wave velocity and albuminuria in patients with type 2 diabetes. J Am Soc Nephrol 16:1069-1075

63. Tanaka M, Babazono T, Takeda M, Iwamoto Y (2006) Pulse pressure and chronic kidney disease in patients with type 2 diabetes. Hypertens Res 29:345-352

64. Cockcroft JR, Wilkinson IB, Evans M et al (2005) Pulse pressure predicts cardiovascular risk in patients with type 2 diabetes mellitus. Am J Hypertens 18:1463-1467 discussion 1468-1469

65. van Popele NM, Westendorp IC, Bots ML et al (2000) Variables of the insulin resistance syndrome are associated with reduced arterial distensibility in healthy non-diabetic middle-aged women. Diabetologia 43:665-672

66. Nakanishi N, Suzuki K, Tatara K (2003) Clustered features of the metabolic syndrome and the risk for increased aortic pulse wave velocity in middle-aged Japanese men. Angiology 54:551-559

67. Choi KM, Lee KW, Seo JA et al (2004) Relationship between brachial-ankle pulse wave velocity and cardiovascular risk factors of the metabolic syndrome. Diabetes Res Clin Pract 66:57-61

68. Scuteri A, Najjar SS, Muller DC et al (2004) Metabolic syndrome amplifies the age-associated increases in vascular thickness and stiffness. J Am Coll Cardiol 43:1388-1395

69. Czernichow S, Bertrais S, Blacher J et al (2005) Metabolic syndrome in relation to structure and function of large arteries: a predominant effect of blood pressure. A report from the SU.VI. MAX. Vascular Study. Am J Hypertens 18:1154-1160

70. Ferreira I, Henry RM, Twisk JW, van Mechelen W, Kemper HC, Stehouwer CD (2005) The metabolic syndrome, cardiopulmonary fitness, and subcutaneous trunk fat as independent determinants of arterial stiffness: the Amsterdam Growth and Health Longitudinal Study. Arch Intern Med 165:875-882

71. Li S, Chen W, Srinivasan SR, Berenson GS (2005) Influence of metabolic syndrome on arterial stiffness and its age-related change in young adults: the Bogalusa Heart Study. Atherosclerosis 180:349-354

72. Nakanishi N, Shiraishi T, Wada M (2005) Brachial-ankle pulse wave velocity and metabolic syndrome in a Japanese population: the Minoh Study. Hypertens Res 28:125-131
73. Schillaci G, Pirro M, Vaudo G et al (2005) Metabolic syndrome is associated with aortic stiffness in untreated essential hypertension. Hypertension 45:1078-1082

74. Seo HS, Kang TS, Park S et al (2005) Insulin resistance is associated with arterial stiffness in nondiabetic hypertensives independent of metabolic status. Hypertens Res 28:945-951

75. Tomiyama H, Koji Y, Yambe M et al (2005) Elevated C-reactive protein augments increased arterial stiffness in subjects with the metabolic syndrome. Hypertension 45:997-1003

76. Whincup PH, Gilg JA, Donald AE et al (2005) Arterial distensibility in adolescents: the influence of adiposity, the metabolic syndrome, and classic risk factors. Circulation 112:1789-1797

77. Ahluwalia N, Drouet L, Ruidavets JB et al (2006) Metabolic syndrome is associated with markers of subclinical atherosclerosis in a French population-based sample. Atherosclerosis 186:345-353

78. Iannuzzi A, Licenziati MR, Acampora C et al (2006) Carotid artery stiffness in obese children with the metabolic syndrome. Am J Cardiol 97:528-531

79. Mulé G, Cottone S, Mongiovi R et al (2006) Influence of the metabolic syndrome on aortic stiffness in never treated hypertensive patients. Nutr Metab Cardiovasc Dis 16:54-59

80. Saijo Y, Yoshioka E, Fukui T, Kawaharada M, Kishi R (2006) Metabolic syndrome, C-reactive protein and increased arterial stiffness in Japanese subjects. Hypertens Res 29:589-596

81. Safar ME, Thomas F, Blacher J et al (2006) Metabolic syndrome and age-related progression of aortic stiffness. J Am Coll Cardiol 47:72-75

82. Tomiyama H, Hirayama Y, Hashimoto H et al (2006) The effects of changes in the metabolic syndrome detection status on arterial stiffening: a prospective study. Hypertens Res 29:673-678

83. Tsubakimoto A, Saito I, Mannami T et al (2006) Impact of metabolic syndrome on brachial-ankle pulse wave velocity in Japanese. Hypertens Res 29:29-37

84. Ferreira I, Boreham CA, Twisk JW et al (2007) Clustering of metabolic syndrome risk factors and arterial stiffness in young adults: The Northern Ireland Young Hearts Project. J Hypertens 25:1009-1020

85. Protogerou AD, Blacher J, Aslangul E et al (2007) Gender influence on metabolic syndrome's effects on arterial stiffness and pressure wave reflections in treated hypertensive subjects. Atherosclerosis 193:151-158

86. Sipila K, Koivistoinen T, Moilanen L et al (2007) Metabolic syndrome and arterial stiffness: the Health 2000 Survey. Metabolism 56:320-326

87. Yokoyama H, Kuramitsu M, Kanno S, Tada J, Yokota Y, Kamikawa F (2007) Relationship between metabolic syndrome components and vascular properties in Japanese type 2 diabetic patients without cardiovascular disease or nephropathy. Diabetes Res Clin Pract 75:200-206

88. Guize L, Thomas F, Pannier B, Bean K, Jego B, Benetos A (2007) All-cause mortality associated with specific combinations of the metabolic syndrome according to recent definitions. Diabetes Care 30:2381-2387

89. Yki-Jarvinen H, Westerbacka J (2007) Insulin resistance, arterial stiffness and wave reflection. Adv Cardiol 44:252-260

90. Giltay EJ, Lambert J, Elbers JM, Gooren LJ, Asscheman H, Stehouwer CD (1999) Arterial compliance and distensibility are modulated by body composition in both men and women but by insulin sensitivity only in women. Diabetologia 42:214-221

91. Salomaa V, Riley W, Kark JD, Nardo C, Folsom AR (1995) Non-insulin-dependent diabetes mellitus and fasting glucose and insulin concentrations are associated with arterial stiffness indexes. The ARIC Study. Atherosclerosis Risk in Communities Study. Circulation 91:1432-1443 
92. Emoto M, Nishizawa Y, Kawagishi T et al (1998) Stiffness indexes $\beta$ of the common carotid and femoral arteries are associated with insulin resistance in NIDDM. Diabetes Care 21:1178-1182

93. van Dijk RA, Bakker SJ, Scheffer PG, Heine RJ, Stehouwer CD (2003) Associations of metabolic variables with arterial stiffness in type 2 diabetes mellitus: focus on insulin sensitivity and postprandial triglyceridaemia. Eur J Clin Invest 33:307-315

94. Olsen MH, Fossum E, Hjerkinn E et al (2000) Relative influence of insulin resistance vs blood pressure on vascular changes in longstanding hypertension. ICARUS, a LIFE sub study. Insulin Carotids US Scandinavia. J Hypertens 18:75-81

95. Sengstock DM, Vaitkevicius PV, Supiano MA (2005) Arterial stiffness is related to insulin resistance in nondiabetic hypertensive older adults. J Clin Endocrinol Metab 90:2823-2827

96. Tomiyama H, Hashimoto H, Hirayama Y et al (2006) Synergistic acceleration of arterial stiffening in the presence of raised blood pressure and raised plasma glucose. Hypertension 47:180-188

97. Ahlgren AR, Lanne T, Wollmer P, Sonesson B, Hansen F, Sundkvist G (1995) Increased arterial stiffness in women, but not in men, with IDDM. Diabetologia 38:1082-1089

98. Pannier B, Guerin AP, Marchais SJ, Safar ME, London GM (2005) Stiffness of capacitive and conduit arteries: prognostic significance for end-stage renal disease patients. Hypertension 45:592-596

99. Hatsuda S, Shoji T, Shinohara K et al (2006) Regional arterial stiffness associated with ischemic heart disease in type 2 diabetes mellitus. J Atheroscler Thromb 13:114-121

100. Kizu A, Koyama H, Tanaka S et al (2003) Arterial wall stiffness is associated with peripheral circulation in patients with type 2 diabetes. Atherosclerosis 170:87-91

101. Taniwaki H, Shoji T, Emoto $M$ et al (2001) Femoral artery wall thickness and stiffness in evaluation of peripheral vascular disease in type 2 diabetes mellitus. Atherosclerosis 158:207-214

102. Huxley R, Barzi F, Woodward M (2006) Excess risk of fatal coronary heart disease associated with diabetes in men and women: meta-analysis of 37 prospective cohort studies. BMJ 332:73-78

103. Kanaya AM, Grady D, Barrett-Connor E (2002) Explaining the sex difference in coronary heart disease mortality among patients with type 2 diabetes mellitus: a meta-analysis. Arch Intern Med 162:1737-1745

104. Hunt KJ, Resendez RG, Williams K, Haffner SM, Stern MP (2004) National Cholesterol Education Program vs World Health Organization metabolic syndrome in relation to all-cause and cardiovascular mortality in the San Antonio Heart Study. Circulation 110:1251-1257

105. McNeill AM, Rosamond WD, Girman CJ et al (2005) The metabolic syndrome and 11-year risk of incident cardiovascular disease in the atherosclerosis risk in communities study. Diabetes Care 28:385-390

106. Sarafidis PA, McFarlane SI, Bakris GL (2006) Gender disparity in outcomes of care and management for diabetes and the metabolic syndrome. Curr Diab Rep 6:219-224

107. Dao HH, Essalihi R, Bouvet C, Moreau P (2005) Evolution and modulation of age-related medial elastocalcinosis: impact on large artery stiffness and isolated systolic hypertension. Cardiovasc Res 66:307-317

108. Zieman SJ, Melenovsky V, Kass DA (2005) Mechanisms, pathophysiology, and therapy of arterial stiffness. Arterioscler Thromb Vasc Biol 25:932-943
109. Creager MA, Luscher TF, Cosentino F, Beckman JA (2003) Diabetes and vascular disease: pathophysiology, clinical consequences, and medical therapy: Part I. Circulation 108:1527-1532

110. Aronson D (2003) Cross-linking of glycated collagen in the pathogenesis of arterial and myocardial stiffening of aging and diabetes. J Hypertens 21:3-12

111. Airaksinen KE, Salmela PI, Linnaluoto MK, Ikaheimo MJ, Ahola K, Ryhanen LJ (1993) Diminished arterial elasticity in diabetes: association with fluorescent advanced glycosylation end products in collagen. Cardiovasc Res 27:942-945

112. Schram MT, Schalkwijk CG, Bootsma AH, Fuller JH, Chaturvedi N, Stehouwer CD (2005) Advanced glycation end products are associated with pulse pressure in type 1 diabetes: the EURODIAB Prospective Complications Study. Hypertension 46:232-237

113. Kass DA, Shapiro EP, Kawaguchi M et al (2001) Improved arterial compliance by a novel advanced glycation end-product crosslink breaker. Circulation 104:1464-1470

114. Wakabayashi I, Masuda H (2006) Association of acute-phase reactants with arterial stiffness in patients with type 2 diabetes mellitus. Clin Chim Acta 365:230-235

115. de Jager J, Dekker JM, Kooy A et al (2006) Endothelial dysfunction and low-grade inflammation explain much of the excess cardiovascular mortality in individuals with type 2 diabetes: the Hoorn Study. Arterioscler Thromb Vasc Biol 26:1086-1093

116. Langenberg C, Bergstrom J, Scheidt-Nave C, Pfeilschifter J, Barrett-Connor E (2006) Cardiovascular death and the metabolic syndrome: role of adiposity-signaling hormones and inflammatory markers. Diabetes Care 29:1363-1369

117. McEniery CM, Qasem A, Schmitt M, Avolio AP, Cockcroft JR, Wilkinson IB (2003) Endothelin-1 regulates arterial pulse wave velocity in vivo. J Am Coll Cardiol 42:1975-1981

118. Wilkinson IB, Qasem A, McEniery CM, Webb DJ, Avolio AP, Cockcroft JR (2002) Nitric oxide regulates local arterial distensibility in vivo. Circulation 105:213-217

119. Kinlay S, Creager MA, Fukumoto M et al (2001) Endotheliumderived nitric oxide regulates arterial elasticity in human arteries in vivo. Hypertension 38:1049-1053

120. Hingorani AD, Cross J, Kharbanda RK et al (2000) Acute systemic inflammation impairs endothelium-dependent dilatation in humans. Circulation 102:994-999

121. Mahmud A, Feely J (2003) Antihypertensive drugs and arterial stiffness. Expert Rev Cardiovasc Ther 1:65-78

122. Williams B, Lacy PS, Thom SM et al (2006) Differential impact of blood pressure-lowering drugs on central aortic pressure and clinical outcomes: principal results of the Conduit Artery Function Evaluation (CAFE) Study. Circulation 113:1213-1225

123. London GM, Asmar RG, O'Rourke MF, Safar ME (2004) Mechanism(s) of selective systolic blood pressure reduction after a low-dose combination of perindopril/indapamide in hypertensive subjects: comparison with atenolol. J Am Coll Cardiol 43: 92-99

124. Susic D, Varagic J, Ahn J, Frohlich ED (2004) Collagen crosslink breakers: a beginning of a new era in the treatment of cardiovascular changes associated with aging, diabetes, and hypertension. Curr Drug Targets Cardiovasc Haematol Disord 4: 97-101

125. Vlachopoulos C, Aznaouridis K, Stefanadis C (2006) Clinical appraisal of arterial stiffness: the Argonauts in front of the golden fleece. Heart 92:1544-1550 